\title{
The Importance of Statistical Indicators for Obtaining the Victory in the Season 2015/2016 of National Basketball Association
}

\author{
Bruno de Almeida Nogueira Lyra ${ }^{1}$, Savio Tardin Badini ${ }^{1}$, Oton Sergio de Andrade \\ Lima ${ }^{1}$, Fabiola Claudia Henrique da $\operatorname{Costa}^{3}$, Carlos Alberto de Azevedo Ferreira ${ }^{1,2,3}$ \\ ${ }^{1}$ Physical Education, Estácio de Sá University - Rio de Janeiro - Brazil \\ ${ }^{2}$ Laboratory of Physiology of Exercise \& Measurements and Evaluation (LAFIEX), Estácio de Sá \\ University - Rio de Janeiro - Brazil \\ ${ }^{3}$ Research Center in Sports Science, Health and Human Development (CIDESD), University of Trás- \\ Os-Montes and Alto Douro - Vila Real - Portugal
}

\begin{abstract}
Throughout its evolution, basketball has increasingly begun to be studied, in relation to the game mode, the tactical and technical volume. It became necessary to observe statistical components to improve the study among the teams, seeking to exploit the weaknesses of the opposing teams and to improve the training of their athletes. This study aimed to identify what are the most important fundamentals to win in NBA games, noting the official statistics of the games of the 2015/2016 season. The analysis of the NBA season games of the North American Basketball League of 2015/2016 was used as a method. It was analyzed 797 regular season games out of a total of 1230 (approximately 65\%) and 46 playoff games out of a total of 85 (approximately $54 \%)$ in the NBA's 2015/2016 season. But the scout serves as a map, as the data that is given to the technician's decision making, which analyzes the other variables of the game and in this point the statistical analysis is very important. The teams that threw more times from the free-throw line and those who converted more had a higher victory rate; the utilization of that point was not significant. Help also proved to be important, especially in the playoffs. The loss of ball possession (turnover) was important when analyzed in the playoffs, as well as the recovery of this possession for theft. The blocks showed relevance in obtaining victory, especially in the playoffs (58.7\%).
\end{abstract}

Keywords: Basketball, Scout, NBA

\section{INTRODUCTION}

Because of the need to practice sport in the harsh winter of Massachusetts, where the practice of sports was done outdoors, in the late nineteenth century, the director of Springfield College Luther Hasley Gullick, called Professor James Naismith and gave him the task of thinking about a game without violence and could also be practiced in the summer to attempt this need. It was then that the teacher created basketball, which has evolved over the years. The sport expanded with great success and in 1936 was introduced to the Olympic Games in Berlin. James Naismith, the creator of the sport, was the one who launched the 'ball to the top' (the starting act) of the first basketball game in the Olympics. ${ }^{1}$

Brazil was one of the first countries to experience basketball, responsible for that was Augusto Shaw two years after his first contact with this new sport. He was invited to teach in the traditional Mackenzie College in São Paulo. Shaw carried in the suitcase some art books and also a basketball.,

In 1933 there was a split in the national sport, the clubs created specialized entities of the several sports. The Brazilian Basketball Federation was born on December 25 (1933). A few years later, in the assembly, the current name of the Brazilian Basketball Confederation (CBB) was approved on December 26 (1941). ${ }^{1}$

In 1946, there was a North American League with the name of Basketball Association of America BAA (Basketball Association of America). This league started with only 11 teams. Over the years 1948 and 1949, some teams that were part of the National Basketball League (National Basketball 
League - NBL) joined BAA. Then in 1949, the BAA became the National Basketball Association (National Basketball Association - NBA), which is known worldwide as today.

Today the NBA has 30 teams divided into 2 conferences and subdivided into divisions. The Eastern Conference consists of the Atlantic, Central and Southeast Division. The Western Conference consists of the Northwest, Pacific and Southwest Division ${ }^{4}$.

Currently, basketball is practiced by more than 300 million people worldwide, in more than 170 countries affiliated to FIBA ${ }^{3,5}$.

Throughout its evolution, basketball has increasingly begun to be studied, in relation to the game mode, tactical and technical volume. This made it necessary to observe statistical components to improve both the study among the teams (seeking to know the opposing team, exploring the weaknesses) and to improve the training of their athletes (observing where this athlete has some deficiency) ${ }^{6}$.

The tool that we find to make this observation is the scout, which is used universally in basketball. The mapping of this information that is generated through the actions of the games, as well as the identification of the factors that lead the team to victory or defeat, can directly influence the final result of a game.

Analyzing statistical indicators in a basketball game is becoming increasingly important as they are correlated to a team's success in a league as it carries with it a history of team strengths throughout its $^{7}$.

The 'scouting' is, according to Throat (1996), "the detection of the characteristics and the opposing team's style of play in order to exploit their weaknesses and counteract its dimensions strong". Cousy and Power Jr. (1985) define the 'scouting' as "a skilled observation studying a future opponent, serving to learn the strategies and behaviors of the players and their weaknesses." 6

Through the scout, the coach can evaluate the athlete as a whole, identifying his deficiencies, the points that need to be better worked on. The analysis of several aspects that are part of a basketball game, gives the technicians the possibility to establish adequate strategies to improve performance both collective and individual ${ }^{6}$.

According to Martin and Gross (1990), game statistics provide objective and relevant information, which serves as a basis for assessing performance. The game indicators observed and analyzed are: assistance, locks, recovery of ball possession, rebound attack, rebound defense, lost balls, faults committed (individual and collective), free throw (right and wrong), two-pitch pitches (right and wrong), three-point pitches (right and wrong) ${ }^{6}$.

This information should be recorded by scouts (recorder), both individual information will be acquired (for each player) and collective (team), so you can later analyze the results. Throughout the game, the scout must be available to the coach, so he can make a reading of the game through statistics, and observe important aspects of the game, in order to make any changes in the tactical part of your team ${ }^{8}$.

During the break of the game, scouts should communicate the technical information that it may not have realized. After the game, the detailed analysis is passed on to the coach so that the coach can perceive how the game was, regardless of the final result, the aspects that were stronger and weaker in the team and also individually, so that they can be corrected in the training sessions?

For this mapping information becomes the most reliable possible, scouts must know the fundamentals of basketball, notice when certain action features a plea be offensive or defensive: attempt to pitch 3 points, 2 points, assistance, offensive rebound, defensive rebound, stolen ball, loose ball (turnover) faults.

According to De Rose Jr. (2005), a pitch is characterized by the attempt to convert to the basket of any part of the court. The attempt may be three points, two points or free throws. An attempted pitch shall be scored whenever there is a clear intention to throw the ball into the basket. The two-point or three-point pitch definition must be based on the referee's signal in the three-point attempt, the umpire raises his arm three-fingered; if converted the referee raises the other arm, indicating that there was the basket ${ }^{10}$. 
It is characterized rebound, the action of regaining possession of the ball after an unconverted pitch, both by attack and defense. For a rebound to be characterized as defensive, it must be picked up after a wrong throw by an opponent. But the attack rebound should be picked up after an error in pitch of a companion $^{11}$.

It is considered an assist, the last pass before a converted throw, but the pitcher must indicate that it will go to the basket immediately. The blocking, according to Pereira (2011) "is the act of preventing the progression of the ball to the basket, diverting its trajectory and preventing the opponent to complete the move." 12

The FIBA website on your Basketball Glossary defines the ball loss (turnover) as the loss of possession of the ball caused by a stolen (steal), an offensive foul, held ball situation or a bad pass ${ }^{5}$.

Also on this site, it shows that the ball stolen (steal), is characterized when you intercept a pass or is the "name of the action," it steals the ball during the dribble or causes the opponent's mistake, recovering possession of the ball.

Data show that it is normal for a team to convert less than $50 \%$ of the game pitches (2 and 3-point pitches are considered), and after the throwing error the defensive or offensive action continues, so the rebound defensive as offensive, is one of the crucial factors for a match ${ }^{13}$.

Daiuto (1983) reports that with the exception of the occasions where the opponent's basket occurs, the most likely way to obtain possession of the ball is on the rebound. Therefore, the team should pay special attention to this foundation in their training, because in a basketball game tends to have a large number of throwing attempts ${ }^{8}$.

De Rose, Gaspar, and Siniscalchi (2002) concluded - in a study where they analyzed the influence of technical fundamentals on the outcome of a match - that defensive rebounds combined with pitch efficiency were important factors for a team-friendly outcome ${ }^{6}$.

Hollinger (2003), through a statistical analysis, considering the pace of play, the defensive efficiency (ED), the offensive efficiency (EO) and the margin of points, reached the conclusion that in the NBA, between the years of 1975 and 2002, no team was champion with game pace 3\% above the league average, and emphasized the importance of possession of the ball by selecting the best pitches ${ }^{14}$.

Melnick (2001) in a study where NBA games were analyzed in the seasons between 1993 and 1998, found a strong correlation between wins and numbers of assists ${ }^{15}$.

Sampaio (1998) conducted a survey with a sample of 484 basketball games and analyzed the most important factors for the final match results, normal, balanced and unbalanced.He noted in the result of his research, that teams that beat their matches, obtained higher numbers of ball possession, which was reinforced due to the greater number of defensive rebounds. In the same survey, it was also observed that the use of three-point pitches were the factors that contributed the most to victory. In normal games, the number of fouls was decisive in determining the final result, the teams that had fewer fouls committed won. It was also identified that the use of the free throws, contribute to the final results of balanced games, the winning teams were more efficient in the line of the free throw ${ }^{16}$.

Oliver (2004) selected four factors that affect the sport of basketball results: pitch efficiency, ball loss number (turnover), offensive rebounds and converted free throws. He came to the conclusion that winning teams in their games reached the highest numbers on three of the four items listed ${ }^{17}$.

This study aims to identify which foundations were most important to obtain the victory in matches of the American League (NBA), watching the official statistics from the season 2015-2016 games, both regular seasons as the playoffs.

\section{METHODS}

The research was characterized as a quantitative descriptive character. The statistical analysis of games from the North American Basketball League's NBA season of 2015/2016 was used as a method.

We analyzed 797 regular season games out of a total of 1230 (approximately 65\%) and 46 games of the playoffs a total of 85 (approximately 54\%) in season 2015/2016 NBA. Matches in which the 
difference between the teams was greater than 12 points during the regular season were not used in this research. In this way, the present study tried to assure the importance of the indicators to obtain the victory due to the proximity of the points on the scoreboard between the teams.

The data was acquired directly from the NBA website, where all game statistics are archived. The score box was analyzed which contains information of each athlete, and also the team as a whole

The following statistical indicators were observed: converted shots (CS), attempted shots (AS), percentage of shots $(\% \mathrm{~S})$, converted two-point shots (2P), two-pitch shots attempted (2PA), percentage of two-point (\%2P), converted three-point shots (3P), three-pitch shots attempted (3PA), percentage of three-point (\%3P), converted free throw (FTM), attempt free throw (FTA), percentage of free throw (\%FT), offensive rebound (OREB), defensive rebound (DREB), total rebounds (REB), assists (AST), loss of possession (TOV), stolen ball (STL), stump (BLK), personal foul (PF). In each game, all the indicators were recorded, observing in which the winning team had an advantage.

A mathematical calculation was performed, since the box score, NBA does not contain data: 2PA, 2P and $\% 2 \mathrm{P}$. For this, the following formula was made: AS - 3PA = 2PA, to define the attempted two pitch throws, and $\mathrm{CS}-3 \mathrm{P}=2 \mathrm{P}$, to define the converted two-throw pitches, since the throws included in the $\mathrm{CS}, \% \mathrm{~S}$ does not include free throws (FT).And the percentage of pitches was calculated, with the formula: $(2 \mathrm{P} / 2 \mathrm{PA}) * 100$.

It was considered statistical data obtained by the box score on the official league site, except the data: pitch two tempted points, throwing two converted points and percentage of throwing two points (which are not entered into this box score), these were calculated using Microsoft Excel for Windows ${ }^{\circledR}$. For inferential analysis of the study data made using the Student's t-test for independent samples (significance level $\alpha=0.05$ ).

\section{RESUltS}

Were analyzed 797 regular season games and 46 games of the 2015-2016 season of the National Basketball Association playoffs. Was calculated a difference of ground between winning and losing teams, plus the number of games in which the winning team got advantage on that basis, the total number was divided by $n=797$ (the regular season) and $n=46$ (in game playoffs), thus obtaining the percentage of the prevalence of each indicator.

Table1. Descriptive Statistics of the regular season and Playoffs

\begin{tabular}{|l|c|c|c|c|c|c|c|c|}
\hline \multicolumn{9}{|c}{ Regular Season } \\
\hline & Winning Team & \multicolumn{2}{c|}{ Losing team } & \multicolumn{3}{c|}{ Winning Team } & \multicolumn{2}{c|}{ Losing team } \\
\hline & M \pm DP & CV & M \pm DP & CV & M DP & CV & M \pm DP & CV \\
\hline CS & $39.1 \pm 4.2$ & 0.11 & $37.3 \pm 4.3$ & 0.12 & $37.5 \pm 3.4$ & 0.09 & $36.0 \pm 3.4$ & 0.10 \\
\hline AS & $84.1 \pm 7.2$ & 0.09 & $85.5 \pm 7.2$ & 0.08 & $83.6 \pm 5.5$ & 0.07 & $84.6 \pm 7.9$ & 0.09 \\
\hline \%S & $46.6 \pm 4.5$ & 0.10 & $43.7 \pm 4.7$ & 0.11 & $44.9 \pm 4.1$ & 0.09 & $42.7 \pm 4.0$ & 0.09 \\
\hline 2P & $30.4 \pm 5.0$ & 0.16 & $29.1 \pm 5.0$ & 0.17 & $27.7 \pm 5.0$ & 0.18 & $27.2 \pm 5.2$ & 0.19 \\
\hline 2PA & $60.5 \pm 8.5$ & 0.14 & $60.9 \pm 8.7$ & 0.14 & $58.0 \pm 7.3$ & 0.13 & $58.6 \pm 8.1$ & 0.14 \\
\hline \%2P & $50.5 \pm 6.0$ & 0.12 & $47.9 \pm 6.0$ & 0.13 & $47.7 \pm 6.3$ & 0.13 & $46.7 \pm 7.5$ & 0.16 \\
\hline 3P & $8.7 \pm 3.3$ & 0.38 & $8.2 \pm 3.2$ & 0.40 & $9.8 \pm 4.2$ & 0.43 & $8.3 \pm 3.8$ & 0.46 \\
\hline 3PA & $23.7 \pm 6.6$ & 0.28 & $24.6 \pm 6.9$ & 0.28 & $25.6 \pm 7.9$ & 0.31 & $25.9 \pm 7.5$ & 0.29 \\
\hline \%3P & $36.6 \pm 9.7$ & 0.26 & $32.9 \pm 8.8$ & 0.27 & $38.1 \pm 11.7$ & 0.31 & $31.0 \pm 9.7$ & 0.31 \\
\hline FTM & $19.1 \pm 6.3$ & 0.33 & $16.9 \pm 5.7$ & 0.34 & $18.8 \pm 5.8$ & 0.31 & $16.5 \pm 5.5$ & 0.33 \\
\hline FTA & $24.9 \pm 8.0$ & 0.32 & $22.5 \pm 7.2$ & 0.32 & $24.7 \pm 6.8$ & 0.28 & $21.8 \pm 7.2$ & 0.33 \\
\hline \%FT & $76.8 \pm 10.1$ & 0.13 & $75.6 \pm 10.7$ & 0.14 & $75.5 \pm 9.5$ & 0.13 & $76.3 \pm 8.9$ & 0.12 \\
\hline OREB & $10.4 \pm 3.8$ & 0.37 & $10.7 \pm 3.9$ & 0.36 & $10.5 \pm 3.6$ & 0.34 & $10.4 \pm 4.1$ & 0.39 \\
\hline DREB & $34.7 \pm 5.0$ & 0.14 & $32.2 \pm 4.8$ & 0.15 & $33.8 \pm 4.8$ & 0.14 & $32.0 \pm 3.9$ & 0.12 \\
\hline REB & $45.0 \pm 6.1$ & 0.14 & $42.9 \pm 6.2$ & 0.14 & $44.3 \pm 5.7$ & 0.13 & $42.4 \pm 5.4$ & 0.13 \\
\hline AST & $22.7 \pm 4.6$ & 0.20 & $21.3 \pm 4.5$ & 0.21 & $20.0 \pm 4.6$ & 0.23 & $18.6 \pm 4.9$ & 0.26 \\
\hline TOV & $13.5 \pm 3.8$ & 0.28 & $14.1 \pm 4.0$ & 0.28 & $11.5 \pm 3.5$ & 0.31 & $12.3 \pm 3.5$ & 0.28 \\
\hline STL & $7.9 \pm 3.0$ & 0.38 & $7.6 \pm 3.0$ & 0.39 & $7.6 \pm 2.8$ & 0.37 & $6.5 \pm 2.3$ & 0.36 \\
\hline BLK & $5.3 \pm 2.6$ & 0.50 & $4.8 \pm 2.5$ & 0.52 & $5.6 \pm 2.6$ & 0.47 & $4.6 \pm 1.9$ & 0.42 \\
\hline Federal Police & $19.7 \pm 4.1$ & 0.21 & $21.4 \pm 4.6$ & 0.22 & $20.1 \pm 3.6$ & 0.18 & $21.9 \pm 4.5$ & 0.21 \\
\hline
\end{tabular}

Mean / Standard Deviation $(M \pm S D)$ Coefficient of variation $(C V)$ 
It was observed that both the regular season and in the playoffs the team that tried to play more pitches ( 2 points and 3 points) was the losing team in the regular season observed the percentage of $60.5 \%$ of the losing teams in the playoffs and 67, 4\%. Regarding the free throw teams that won the matches, they threw more (56.6\% regular season and playoffs $56.5 \%)$ and converted more $(58.09 \%$ regular season and playoffs $60.9 \%$ ), however, is analyzed the free - throw percentage, the data showed no relevance where the regular season only $51.2 \%$ of the winning teams got advantage in this foundation and in the playoffs $50 \%$.

Also in relation to pitches, significant data were observed for three - point shot, especially in the playoffs where $69.6 \%$ of games where the use of three points was higher, the team got the win in the regular season the values were $60.6 \%$ which is also an expressive fact. Confirming the thesis of Sampaio (1998), where he found expressive data related to three-point pitches ${ }^{18 .}$

In the regular season the percentage of two - point shooting was also important, in which $63.5 \%$ of the games, the team that won the victory had advantage on this foundation, however, in the playoffs obtained no difference, because $50 \%$ of the games the winning team got advantage and $50 \%$ of the games to lose.

As for the rebounds, defensive shown to be important for achieving victory in the regular season were $63.9 \%$ where the winning team got an advantage in the playoffs and $60.9 \%$. When we observed the general rebounds (defensive + offensive), only in the regular season showed relevance with 59\%, contrary to the thesis of Oliver (2004), where he said that one of the most important factors to obtain the victory was the offensive rebound. And confirming the thesis of Reis (2008); Daiuto (1983) and De Rose, Gaspar and Siniscalchi (2002), which said that one of the most important factors for the victory was getting the ball, and as in a basketball game, normally, the percentage of general pitches is less than $50 \%$, the rebound becomes an important factor for the repossession ${ }^{17,13,8,6,18}$.

The assists proved decisive in getting the victory, especially when it comes to the playoff, where he took victory in $63 \%$ of games where the team got an advantage on this foundation, the regular season, were $56.6 \%$ of the games. Confirming, the study by Melnick (2004), although this present study analyzed this foundation differently ${ }^{15}$.

The turnover (loss of ball) is also an important indicator when analyzing the playoffs $(56.5 \%$ of the games, had less loss of possession), the regular season, showed no relevance.

The ball was stolen also contributed to a high degree for the win in the playoffs (63\% of the games where the team won the victory), the regular season, showed no relevance.

The lock (or popularly known as play), was important in the regular season were $52.1 \%$ of games in which the winning team got an advantage in the playoffs and were $58.7 \%$.

It was noted that the personal fouls are also important factors in the regular season the team made less foul was the winner in $58.3 \%$ of the games in the playoffs and this number grows further, reaching $67.4 \%$ of the games.

Table2. Inferential statistics, regular season and Playoffs

\begin{tabular}{|l|c|c|}
\hline & Regular Season & Playoffs \\
\hline CS & Test T & Test T \\
\hline AS & 0.00 & 0.04 \\
\hline \%S & 0.00 & 0.49 \\
\hline 2P & 0.00 & 0.01 \\
\hline 2PA & 0.00 & 0.69 \\
\hline \%2P & 0.29 & 0.73 \\
\hline 3P & 0.00 & 0.53 \\
\hline 3PA & 0.00 & 0.08 \\
\hline \%3P & 0.01 & 0.82 \\
\hline FTM & 0.00 & 0.00 \\
\hline
\end{tabular}


Bruno de Almeida Nogueira Lyra et al.

\begin{tabular}{|l|c|c|}
\hline \hline FTA & 0.00 & 0.05 \\
\hline \%FT & 0.02 & 0.68 \\
\hline OREB & 0.08 & 0.83 \\
\hline DREB & 0.00 & 0.06 \\
\hline REB & 0.00 & 0.11 \\
\hline AST & 0.00 & 0.16 \\
\hline TOV & 0.00 & 0.26 \\
\hline STL & 0.05 & 0.04 \\
\hline BLK & 0.00 & 0.04 \\
\hline Federal Police & 0.00 & 0.05 \\
\hline
\end{tabular}

In generally converted shots (CS), it was observed that obtained importance in the playoffs and the regular season, both descriptive statistics as the reference statistic. Already in general attempted shots (AS), only in the regular season, referential statistical significance obtained in the playoffs did not achieve statistical significance. And the percentage of general pitches got importance in both statistics (descriptive and referential), both the regular season and in the playoffs.

Pitches in two converted points (2P), noted the importance in two statistical types (descriptive and referential), only in the regular season, the playoffs did not achieve statistical significance. In relation to the attempted pitches (2PA), it did not achieve statistical significance, not the regular season and not in the playoffs. When analyzed the percentage of two - point shots in the regular season showed statistical significance in both descriptive and in reference, already in the playoffs did not show statistical significance.

Regarding pitches three points converted (3P), the regular season, showed significance only in reference statistics and in the playoffs showed significance only on descriptive statistics. When the three-point pitches (3PA) were analyzed, relevance was observed only in the regular season, in relation to referential statistics. By analyzing the percentage of three - point shots (\%3P) showed relevance both the regular season and in the playoffs in descriptive and referential statistics.

By analyzing the pitches of converted free throw (FTM), the regular season, showed the relevance descriptive and referential statistics, since when we observe the playoffs showed significance only on descriptive statistics. Regarding the free throw shots attempted in both the regular season and in the playoffs, showed significance in statistics (descriptive and reference). When we look at the percentage of free throw shooting, only the regular season showed relevance in descriptive statistics and reference in the playoffs showed no relevance.

Offensive rebounds showed no relevance nor in the regular season and not in the playoffs. Already defensive rebounds in the regular season showed relevance both descriptive statistics as the reference, and in the playoffs, showed only on descriptive statistics. When analyzed the general rebounds (defensive + offensive), only showed relevance in the regular season (in both descriptive and referential statistics).

Assists showed relevance in the regular season both descriptive statistics as a reference, already in the playoffs showed significance only on descriptive statistics.

The turnovers (ball losses) showed significance in the regular season compared to reference statistics and in the playoffs in descriptive statistics.

By observing the ball stolen (steals), the regular season showed significance only in reference statistics but when analyzed in the playoffs showed relevance both descriptive statistics as the benchmark.

Locks and personal fouls, showed relevance both the regular season and in the playoffs in descriptive and referential statistics.

Table 3 shows the percentage in which the winning team had an advantage over the losing team in the presented Foundation. The regular season had a total of 797 games while the playoffs had 46 analyzed games. 
The Importance of Statistical Indicators for Obtaining the Victory in the Season 2015/2016 of National Basketball Association

Table3. Regular Season and Playoffs Analysis Result

\begin{tabular}{|l|l|l|l|l|}
\hline Regular Season & & \multicolumn{3}{l|}{ Playoffs } \\
\hline$\%$ S & $72.6 \%$ & & $\% 3 \mathrm{P}$ & $69.6 \%$ \\
\hline DREB & $63.9 \%$ & & $\%$ S & $69.6 \%$ \\
\hline CS & $63.7 \%$ & Federal Police & $67.4 \%$ \\
\hline$\% 2 \mathrm{P}$ & $63.5 \%$ & STL & $63.0 \%$ \\
\hline$\% 3 \mathrm{P}$ & $60.6 \%$ & AST & $63.0 \%$ \\
\hline REB & $59.0 \%$ & DREB & $60.9 \%$ \\
\hline Federal Police & $58.3 \%$ & FTM & $60.9 \%$ \\
\hline FTM & $58.1 \%$ & BLK & $58.7 \%$ \\
\hline AST & $56.6 \%$ & CS & $58.7 \%$ \\
\hline FTA & $56.6 \%$ & FTA & $56.5 \%$ \\
\hline 2P & $55.3 \%$ & 3P & $56.5 \%$ \\
\hline BLK & $52.1 \%$ & TOV & $56.5 \%$ \\
\hline$\%$ FT & $51.2 \%$ & F2P & $50.0 \%$ \\
\hline 3P & $49.9 \%$ & FT\% & $50.0 \%$ \\
\hline TOV & $49.8 \%$ & 2P & $50.0 \%$ \\
\hline STL & $47.2 \%$ & REB & $45.7 \%$ \\
\hline 2PA & $46.7 \%$ & OREB & $45.7 \%$ \\
\hline 3PA & $44.9 \%$ & 3PA & $43.5 \%$ \\
\hline OREB & $43.7 \%$ & 2PA & $43.5 \%$ \\
\hline AS & $39.5 \%$ & AS & $32.6 \%$ \\
\hline
\end{tabular}

The study showed that the factors that most contributed to the victory in the NBA's 2015-2016 season were: Taking advantage of the general pitches (better selection of these - teams that tried less and converted more), the use of three-point pitches showed great relevance in the regular season $(60.6 \%)$, but mainly in the playoffs (being the foundation more important in this stage of the season, with $69.6 \%$ ), defensive rebounds (for obtaining of possession). The teams have committed fewer personal fouls (PF) in 58.4\% of regular season games, and gained the victory in the playoffs showed even greater relevance, because in $67.4 \%$ of the winning team games committed fewer fouls.

\section{Conclusions}

Statistical analysis within sports has shown total importance in relation to the preparation of a team, as well as the study of the opposing team. The main tool for this analysis is the scout that generates a range of information for the technician of a team and giving support for decision-making, whether in relation to the current game or staff training.

It is clear that statistical data alone do not translate a victory because if we analyze the numbers coldly we are making a mistake because a pitch that is given free of marking is different from one where the marking is on top, but when we analyze statistically counts as one action. But the scout serves as a map, such as roads that are given to us for technical decision-making, which analyzes the other variables of the game and at this point the statistical analysis shown important.

The teams that threw more of the line of the free throw and those that converted more, had a greater index of victory, already the use of this pitch was not significant. Assists also showed to be important, especially in the playoffs. The loss of the ball (turnover) showed significant when analyzed playoff, as well as the recovery of this possession of stolen through the ball (steal). The blocks (block) showed significance in getting the victory, especially in the playoffs $(58.7 \%)$.

It is recommended to perform more accurate studies on the level of the game (compared to final campaigns of times), the statistics related to home games and away from home (home advantage). This season there have been two extraordinary situations, the team Golden State Warriors who made the best campaign in history in the regular season and the team the Cleveland Cavaliers in the playoffs became a series of $3 \times 1$ to $4 \times 3$ situations those that deserve notice and analysis.

It is also recommended studies accompanying the next seasons so that it can be observed the most important fundamentals if it remains, or if it was characteristic of this season. 


\section{REFERENCES}

[1] Confederação Brasileira de Basketball, 2006. Avaible at <http://www.cbb.com.br/PortalCBB/ OBasquete/BasqueteBrasil>. Accessed 17/10/2016.

[2] Brown F. Caderno técnico - Didático basquetebol. Brasília: Secretária de Educação Física e Desporto. 1983.

[3] Cousy B, Power Jr. FG. Basketball: concepts and techniques. Boston: Allin and Bacon. 1985.

[4] NBA Brasil. Available at <http://www.nba.com/brasil/equipesnba.html>, accessed 11/25/2016.

[5] FIBA Glossary. Available at <http://www.fibaeurope.com/cidUD-XflK3IQg14t8JKzEA00.html>

[6] De Rose Junior D, Gaspar A, Siniscalchi M. Análise estatística do desempenho técnico coletivo no basquetebol. Revista Digital Buenos Aires. 2002; 8(49). Avaible at <http://www.efdeportes. com>.

[7] Dantas JPF, Filho JCBV. The technical indicators of the game and classification: a study on the 16 national men's basketball championship. Educação Física em Revista. 2008; 2(1). Avaible at: <http:// portalrevistas.ucb.br/index.php/efr/article/view/890/813>.

[8] Daiuto, M. Basquetebol: metodologia de ensino. 5 edition. São Paulo: Editora Brasipal Ltda. 1983.

[9] Araujo PAB, Cáceres JMS, Ulbrich A, Monte, FG. The use of scout in basketball. Revista Digital Buenos Aires. 2010; 14(140). Avaible at 〈http://www.efdeportes.com>.

[10] De Rose Junior D, Tricoli, V. Basquetebol: uma visão integrada entre ciência e prática. Barueri: Manole, 2005.

[11] 11. Ranchette D, Mercadante L. A Importância do Rebote no Basquetebol Moderno. Revista do Centro Universitário. 2001; 1.

[12] PEREIRA J., 2011. Termos. Available at: <http://www.otempo.com.br/superfc/others/tocoenterrada-assist\%C3\%A3-Agua-bandeja-conhe\%C3\%A7a-os-termos-utilizados- in-basketball1.183097>.

[13] Reis C. Ações e termos defensivos do basquetebol. Revista Digital - Buenos Aires. 2008; 13(126). - Noviembre de 2008. Avaible at <http://www.efdeportes.com>.

[14] Hollinger, J. Pro basketball prospectus. Virginia: Brassey's Inc. 2003.

[15] Melnick MJ. Relationship between team assist and win-loss Record in the National Basketball Association. Perceptual and Motor Skills. 2001; 92: 595-602.

[16] Sampaio AJ. Los indicadores estadísticos mas determinantes em el resultado final em los partidos de basquetbol. Lecturas Educación Física Revista Digital, Buenos Aires. 1998; 3(11).

[17] Oliver D. Basketball on paper. Rules and tools for performance analysis. Washington, DC: Brassey's, Inc. 2004.

[18] Angel Gomes M, Lorenzo A; Sampaio J, Ibáñez SJ; Ortega E. Game-related statistics that discriminate winning and losing teams from the Spanish men's professional basketball teams. Coll Antropol. 2008; 32(2): 451-6.

Citation: Bruno de Almeida, Nogueira Lyra et al. "The Importance of Statistical Indicators for Obtaining the Victory in the Season 2015/2016 of National Basketball Association." International Journal of Sports and Physical Education (IJSPE), vol 3, no. 3, 2017, pp. 27-34. doi:http://dx.doi.org/10.20431/24546380.0303004.

Copyright: (C) 2017 Authors. This is an open-access article distributed under the terms of the Creative Commons Attribution License, which permits unrestricted use, distribution, and reproduction in any medium, provided the original author and source are credited. 